EDITORIAL

\title{
Picosecond laser applications in aesthetic dermatology
}

\author{
Nasrin Saki
}

Molecular Dermatology Research Center, Shiraz University of Medical Sciences, Shiraz, Iran

$\mathrm{T}$ The time needed for a tissue to cool halfway down to its initial temperature is the thermal relaxation time (TRT) of that tissue. In order to reach the goal of selective photothermolysis, tissue ablation by laser beam should be fast with pulse duration shorter than or nearly equal to the TRT of the skin targets. The introduction of concept-selective photothermolysis by pulsed lasers was a breakthrough in laser surgery by minimizing the risks of dyspigmentation and scarring associated with old continuous wave lasers ${ }^{[1]}$.

Q-switched (QS) lasers are defined by extremely short, nanosecond pulses that induce photomechanical and photoacoustic tissue interactions. This short pulse duration limits the damage to the lysosome ${ }^{[2]}$. QS Lasers with pulse duration of 5 to $100 \mathrm{~ns}$ have been the main lasers for tattoo removal since the 1980s. Since most tattoo particles' size are approximately $100 \mathrm{~nm}$, corresponding to a thermal relaxation time of less than $10 \mathrm{~ns}$, picosecond (PS) lasers could be more effective than QS lasers, theoretically. Clinical trials have reported the efficacy and safety of PS lasers in the treatment of multicolored and recalcitrant tattoos ${ }^{[3]}$.

Reiter et al. in 2016 designed a great systematic review regarding the use of PS lasers for tattoo removal. They concluded that using a PS laser causes a drastic photoacoustic effect that may be beneficial for the removal of a wider variety of tattoo colors, in theory. The ability of PS lasers to remove multicolored tattoos was shown for green, yellow, red, and purple tattoos. However, the findings was not directly compared with the results of the traditional QS lasers ${ }^{[3]}$.

As a new technology, PS lasers are receiving more attention in aesthetic dermatology, and their application for other cosmetic problems, beyond tattoos, are being investigated by many dermatologists.

Brauer et al. in 2015 demonstrated favorable results in acne scar treatment with the 755-picosecond laser plus diffractive lens array. Improvements in texture and pigmentation of the surrounding skin were also noted, suggesting there may be favorable results for indications other than scarring ${ }^{[4]}$.

In another study by Petersen et al. in 2016, wound healing after incision with a novel picosecond infrared laser (PIRL) was compared with different surgical techniques in a rat skin model. They concluded that PIRL results in minimal scarring and improves aesthetic outcomes. The resection of skin neoplasms, hypertrophic scars and keloids, particularly, could be interesting fields for PIRL application ${ }^{[5]}$.

Ohshiro et al. in 2016 designed a retrospective study investigating the results of PS laser for the treatment of dermal melanocytosis in Asians. They concluded that PS lasers, both the 1064-nm Nd:YAG and the 755-nm alexandrite, are beneficial for the removal of dermal melanocytosis with minimal side effects ${ }^{[6]}$.

The effectiveness of the PS 755-nm alexandrite laser in the treatment of benign pigmentary lesions, especially Nevus of Ota, was also shown by Chan et al. It was demonstrated that PS laser is associated with a lower risk of post-inflammatory hyperpigmentation in Asians ${ }^{[7]}$.

In 2017, Weiss et al. designed an interesting prospective, blinded study investigating the effectiveness of a novel diffractive lens array using a PS 755-nm alexandrite laser in the treatment of facial wrinkles. They have found it safe and highly effective for the improvement of rhytides and other signs of skin aging ${ }^{[8]}$.

In summary, PS lasers have been introduced as a novel modality mostly as a treatment for challenging pigmented lesions or tattoos. Nevertheless, their spectrum of beneficial effects in cosmetic dermatology seems to go further day by day.

However, there are still some controversies regarding their cost and efficacy, and further well-designed studies are needed to evaluate the efficacy of this novel technology.

Copyright (C) 2017 Saki N. This is an Open Access article distributed under the terms of the Creative Commons Attribution-NonCommercial 4.0 International License (http://creativecommons.org/licenses/by-nc/4.0/), permitting all non-commercial use, distribution, and reproduction in any medium, provided the original work is properly cited. 


\section{Conflict of interest}

The author declares no potential conflict of interest with respect to the research, authorship, and/or publication of this article.

\section{References}

1. Sakamoto FH, Avram MM, Anderson RR. Lasers and other energy technologies principles and skin interactions. $3^{\text {rd }}$ ed. In: Bolognia JL, Jorizzo JL, Schaffer JV, (editors). Dermatology. Spain: Mosby Elsevier; 2012. p. 2251-2253.

2. Zachary CB, Rofagha R. Laser therapy. $3^{\text {rd }}$ ed. In Bolognia JL, Jorizzo JL, Schaffer JV (editors). Dermatology. Spain: Mosby Elsevier; 2012. p. 2267-2268.

3. Reiter O, Atzmony L, Akerman L, Levi A, Kershenovich $\mathrm{R}$, et al. Picosecond lasers for tattoo removal: A systematic review. Lasers Med Sci 2016; 31(7): 1397-1405. doi: 10.1007/s10103-016-2001-0.

4. Brauer JA, Kazlouskaya V, Alabdulrazzaq H, Bae YS, Bernstein LJ, et al. Use of a picosecond pulse duration laser with specialized optic for treatment of facial acne scarring. JAMA Dermatol 2015; 151(3): 278-284. doi: 10.1001/jamadermatol.2014.3045.

5. Petersen H, Tavakoli F, Kruber S, Münscher A, Gliese A, et al. Comparative study of wound healing in rat skin following incision with a novel picosecond infrared laser (PIRL) and different surgical modalities. Lasers Surg Med 2016; 48(4): 385-391. doi: 10.1002/1sm.22498.

6. Ohshiro T, Ohshiro T, Sasaki K, Kishi K. Picosecond pulse duration laser treatment for dermal melanocytosis in Asians: A retrospective review. Laser Ther 2016; 25(2): 99-104. doi: 10.5978/islsm.16-OR-07.

7. Chan JC, Shek SY, Kono T, Yeung CK, Chan HH. A retrospective analysis on the management of pigmented lesions using a picosecond 755-nm alexandrite laser in Asians. Lasers Surg Med 2016; 48(1): 23-29. doi: 10.1002/lsm.22443.

8. Weiss RA, McDaniel DH, Weiss MA, Mahoney AM, Beasley KL, et al. Safety and efficacy of a novel diffractive lens array using a picosecond $755 \mathrm{~nm}$ alexandrite laser for treatment of wrinkles. Lasers Surg Med 2017; 49(1): 40-44. doi: 10.1002/lsm.22577.

Keywords: Picosecond laser; dermatology, aesthetic

Citation: Saki N. Picosecond laser applications in aesthetic dermatology. J Surg Dermatol 2017; 2(T1):107-108; http://dx.doi.org/10.18282/jsd.v2.it1.142.

Received: $2^{\text {nd }}$ March 2017; Published Online: $15^{\text {th }}$ March 2017

Correspondence to: Nasrin Saki, Molecular Dermatology Research Center, Shiraz University of Medical Sciences, Shiraz, Iran, nasrinsa85@yahoo.com. 